\title{
STUDY ON SAFETY MANAGEMENT OF SMALL AND MEDIUM SCALE INDUSTRIES IN TAMILNADU
}

\author{
B.Rajarethinam ${ }^{1}$, A.Elavarasi ${ }^{2}$ \\ ${ }^{1}$ Industrial Safety Engineering, Department of Mechanical Engineering, Knowledge Institute of Technology, Salem, \\ Tamilnadu \\ ${ }^{2}$ Assistant Professor, Department of Mechanical Engineering, Knowledge Institute of Technology, Salem, Tamilnadu
}

\begin{abstract}
The small and medium scale industries(SMI) have immense growth in the recent years due to the social and economical development of the country, but the safety aspects followed in the SMI are very poor, and it becomes highly risky to the employees life, so safety aspects in SMI requires huge amount of improvement. In this thesis we propose a behavior of small and medium scale industry for safety management approach and analysis of its characteristics in Tamilnadu and also suggesting modern safety Equipments to reduce the accident rate and incident rate of SMI, highlighting the safety awareness in SMI from the management level to the employee in order to improve the safety management in SMI's.
\end{abstract}

Keywords: Safety Behavior, Safety Culture, Safety Performance, Safety development.

\section{INTRODUCTION}

In recent years number of industrial accident took place in the small and medium scale industries due to lag of environmental safety and unaware of industrial accidents. Management must focus on their safety improvement. According to Heinrich statement, the industrial accident that $88 \%$ of accidents were caused by human unsafe behavior, $10 \%$ accidents were caused by the industrial unsafe environment and $2 \%$ accidents were attributed to other factors. Nowadays more number of industrial accidents happens due to the human error. Therefore it is important thing to analysis the human behavior for accident prevention.

[1].There are some methods to prevent such an industrial accident and the most effective method is to develop the human behavior and to improve the safety culture in industry. From the various studies it is clear that one of the causes for initiation of industrial accident is management system. For improving the safety culture and behavior of the employee, industry needs to provide training, education, meeting etc. For this purpose the industry is in the position to spend money for the following aspects Training, Education Meeting. Communication also plays a major role in accident because the performance of communication from top level to low level management is very poor. This paper deals about causes of accident and from this causes, it helps to rectify the problems and it tends to increase the performance of safety culture and behavior of the employee[2]

\section{METHODOLOGY}

Safety management system approach three safety systems to the improvement and reduce the accidents. In this paper suggested some systematic approach to the safety

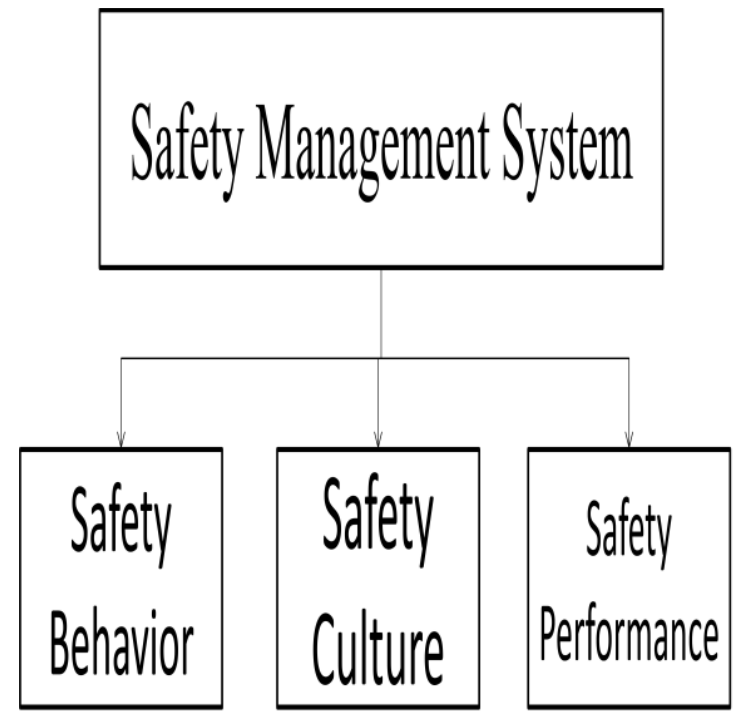

Fig 1.Safety management system

\subsection{Safety Behavior}

Safety behavior is more important to their small and medium scale industries. It is necessary to identify all behavior activity and then differentiate from the unsafe and safe behavior. After the respective risk all behavior must be made and arranged in order. The identification of conclusion must be passing to all the workers. Safety behavior is defined as everything a person does in the observable in the working place. Safety behavior describe the support of safety training, motivation and education that activities to be carried out by the employees. Safety behavior is the way to reduce the accident at the work place and indirectly outcomes from the event accident occurred. Safety training is given to all employees yearly once. New employee must attend the safety training before going to the respective work. Safety management should concentrate more to the 
safety motivation to encourage the workers to follow the safety aspects in the industry[2]. There are two type of motivation Positive reinforcement, Negative reinforcement. Positive reinforcement can be implemented by means of Rewards, Bonus, and Job promotion. Negative reinforcement is Criticize and threatening the employees to perform the work safely. Safety education is given to all employees to know their top to bottom level of safety condition. Safety behavior observation is the most important process of correcting the unsafe behaviors, which need attach importance to communication techniques. Weekly once safety education must be given to everyone to increase the performance of safety among the workers.

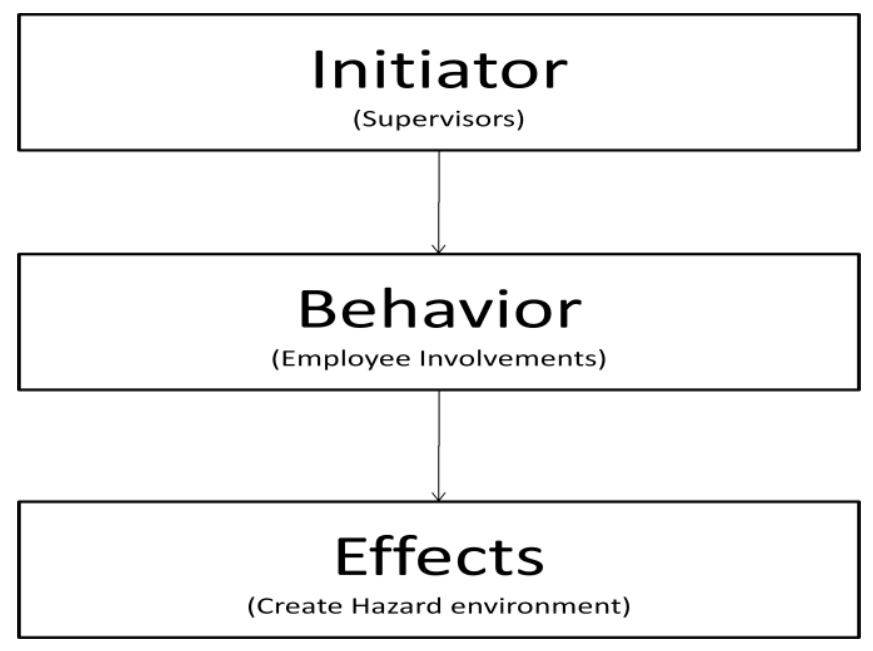

\subsection{Safety Culture}

Every industries must develop their own safety policy depend upon their safety culture and improvement based. It is more important to small and medium scale industries .Related to the safety aspects management organizes a committee to develop the future status of the safety aspects. Committee must identified a critical factor in understand and explaining the work related behavior of employee. All the management takes the initial work of identifying the hazard at the workplace. The aim of the management is to minimize their risk at the workplace and eliminate the hazard .Periodic evaluation at their workplace survey is must. Every industries must evaluate their design depend upon their standards. The main objective of safety culture is to focus on the working environment and welfare facilities[3]. Motivation is one of the most important processes for management implementation. One of the most important implementation safeguards for this process is to set up the on duty behavior observer and ensure the employees could take the position alternatively. Only this could ensure the full involvement of employees and improve their safety awareness According to the Act 1948, suggested the cleanliness of work environment must clean and disposal waste concentrate more things to their environment condition. Every industry must develop their good welfare facilities in the surrounding. The relationship between the management and workers must be in good condition. It improves the better safety culture in the industries.

\subsection{Safety Performance}

Daily inspection gives more safety development recommendation and improves their industry environment. It eliminates all the hazards periodically to reduce the accident rate. It also supports their zero accident system in the industries. Safety audit is the next concern to the safety system from top level to the low level, it analysis the safety system pin out their error in their particular field and also the best safety improvement condition to the industries. Meanwhile, encourage and reward the safe behaviors and achieve the objective of correcting the unsafe behaviors. Safety audit depends upon their questionnaire, individual interview, collecting the suggestion to their employee and give proper solution to all the workers. Accident report given to respective person in the industries. Mainly it is based on their two types: reportable and non-reportable accident, it is based upon the injury based thing. Analyses the each thing in the accident part report itself submit their initial to the end conclusion part of their accident. The main objective of accident investigation is to know the purpose of accident, impact of accident and causes of accident. The purpose of accident investigation is to determine the sequence of leading to failure find the method to prevent accident from recurring. Basic two types of accident: direct and indirect consequences. Develop a policy for accident investigation method to solving the problem like job hazard analysis, sequence diagram and change the systematic analysis. Incident investigation are periodic condition by improves the safety management in the analysis of past accident record and eliminate all hazard at the workplace. According to the standards, management must maintain the proper shift time to the workers. It will help to reduce the mentality and stresses of the workers.

\section{RECOMMENDATIONS AND SUGGESTIONS}

In current affairs, the small and medium scale industries are unaware of the industrial accident and more lack in the safety aspects .Here some suggestion and recommendation are given to the SMI safety policy must implement to all industries, safety training to all workers, on-site emergency plan, off-site emergency plan, mock drill conducted periodically. Firefighting equipment must be placed in the hazardous area. The industrial workers must follow all the safety thing and rules to keep the workplace clean and neat.

\section{CONCLUSIONS}

This paper suggested the need of safety behavior, culture and performance. The study has shown that an employee safety in top level to low level manner, it highly recommended to all SMI. However the safety management is still at very beginning stage in our state. This recommendation will help more to improve the safety aspects for all SMI. Many approach were implemented related to the safety by these safety concepts to all SMI have much better safety in workplace. This study taken as a ground work to improve safety management on SMI. 


\section{REFERENCES}

[1]. Sulastre Mat Zin* and Faridah Ismail, (2012), Employers' Behavioural Safety Compliance Factors toward Occupational, Safety and Health Improvement in the Construction Industry, journal of Procedia Engineering 36, $742-751$.

[2]. Vijayakumar, T. (2007). Achieve total Safety Culture through Behaviour Based Safety, Proceeding of the 10th Conference and Exhibition of National Institute of Occupational Safety and Health (NIOSH), Malaysia, 303313.

[3]. YUAN Xiongjun*, WANG Kaiquan.,(2012) Study on safety management of small and medium- sized enterprises based on BBS,journal of Procedia Engineering $45,208-213$. 